\title{
DESENVOLVER E MODERNIZAR: A CRIAÇÃO DO MINAS INSTITUTO DE TECNOLOGIA (MIT) EM GOVERNADOR VALADARES (MG) E A FORMAÇÃO DE PROFESSORES
}

\author{
Ana Catarina Cantoni Roque* \\ Maria Laura Magalhães Gomes **
}

\section{RESUMO}

O artigo focaliza a criação e os momentos iniciais do Minas Instituto de Tecnologia (MIT) em Governador Valadares (MG), no contexto da expansão do ensino superior privado brasileiro, no final dos anos 1960. O texto apresenta resultados de uma pesquisa cujo objetivo foi construir uma história do curso de licenciatura em Matemática do MIT. A metodologia da História Oral foi usada para a realização de 16 entrevistas com antigos professores e estudantes da instituição. Foram também consultados pareceres do Conselho Federal de Educação, jornais, históricos escolares e outros documentos institucionais do MIT. Os cursos de licenciatura em Ciências Exatas, implantados para aproveitar professores e instalações dos cursos de Engenharia, bem como para

\footnotetext{
* Instituto Federal de Minas Gerais (IFMG), Belo Horizonte/MG, Brasil.

**Universidade Federal de Minas Gerais (UFMG), Belo Horizonte/MG, Brasil.
} 
gerar recursos financeiros, desempenharam papel coadjuvante no cenário modernizador e desenvolvimentista do Brasil sob o regime militar.

Palavras-chave: desenvolvimento, modernização, regime militar, ensino superior, história oral.

\title{
DESARROLLAR Y MODERNIZAR: LA CREACIÓN DEL MINAS INSTITUTO DE TECNOLOGIA (MIT) EN GOVERNADOR VALADARES Y LA FORMACIÓN DE DOCENTES
}

\section{RESÚMEN}

El artículo se centra en la creación y los momentos iniciales del Instituto Tecnológico de Minas (MIT) en Governador Valadares (MG), en el contexto de la expansión de la educación superior privada en Brasil, a fines de la década de 1960. El texto presenta los resultados de una investigación cuyo objetivo fue construir una historia de la carrera de matemáticas en el MIT. Se utilizó la metodología de Historia Oral para realizar 16 entrevistas a antiguos profesores y alumnos de la institución. También se consultaron opiniones del Consejo Federal de Educación, periódicos, registros escolares y otros documentos institucionales del MIT. Los cursos de grado en Ciencias Exactas, implementados para aprovechar los profesores y las instalaciones de los cursos de Ingeniería, así como para generar recursos económicos, jugaron un papel de apoyo en el escenario modernizador y de desarrollo de Brasil bajo el régimen militar.

Palabras clave: desarrollo, modernización, régimen militar, educación superior, historia oral.

\section{DEVELOPING AND MODERNIZING: THE CREATION OF MINAS INSTITUTO DE TECNOLOGIA (MIT) IN GOVERNADOR VALADARES AND THE TRAINING OF TEACHERS}

\begin{abstract}
The article focuses on the creation and early moments of the Minas Institute of Technology (MIT) in Governador Valadares (MG), in the context of the expansion of Brazilian private higher education, in the late 1960s. The text presents conclusions of a research whose objective was to build a history of the mathematics course at MIT. The Oral History methodology was used to conduct 16 interviews with former professors and students at the institution. Opinions from the Federal Education Council, newspapers, school records and other institutional documents from MIT were consulted as well. The degree courses in Exact Sciences, implemented for taking advantage of professors and facilities of Engineering courses, as well as to generate financial resources, played a supporting role in the modernizing and developmental scenario of Brazil under the military regime.
\end{abstract}

Keywords: development, modernization, military regime, higher education, oral history. 


\section{DÉVELOPPER ET MODERNISER: LA CRÉATION DU MINAS INSTITUTO DE TECNOLOGIA (MIT) À GOVERNADOR VALADARES ET LA FORMATION DES ENSEIGNANTS}

\section{RÉSUMÉ}

L'article se concentre sur la création et les premiers moments du Minas Institute of Technology (MIT) à Governador Valadares (MG), dans le contexte de l'expansion de l'enseignement supérieur privé brésilien, à la fin des années 1960 . Le texte présente les résultats d'une recherche dont l'objectif était de construire une histoire du cours de mathématiques au MIT. La méthodologie d'histoire orale a été utilisée pour mener 16 entretiens avec d'anciens professeurs et étudiants de l'institution. Les avis du Conseil Fédéral de l'Éducation, des journaux, des registres scolaires et d'autres documents institutionnels du MIT ont également été consultés. Les cours en sciences exactes, mis en œuvre pour tirer parti des enseignants et des installations des cours d'ingénierie, ainsi que pour générer des ressources financières, ont joué un rôle de soutien dans le scénario modernisateur et développementaliste du Brésil sous le régime militaire.

Mots-clés: développement, modernisation, régime militaire, enseignement supérieur, histoire orale. 


\section{INTRODUÇÃO}

Nos anos 1950, o Brasil vivenciou um grande crescimento, que pôde ser percebido no aumento da taxa de urbanização, na expansão industrial e no aumento demográfico. Nesse contexto, uma parcela cada vez maior de jovens conseguia concluir o ensino secundário e houve um acréscimo significativo na procura pelo ensino superior. As vagas disponíveis nesse nível de ensino não bastavam para atender à demanda em expansão, acarretando uma grave crise na oferta de vagas e dando lugar para a insatisfação dos jovens, que começaram a questionar a obsoleta estrutura universitária. Além da quantidade de vagas, estudantes, professores e demais interessados discutiam a estrutura básica das universidades, baseada no sistema de cátedra vitalícia. Criticava-se também o fato de as universidades não fazerem pesquisa e não produzirem suficiente de mão-de- obra qualificada.

Com a onda de crescimento dos anos 1950, os debates sobre reformas no Brasil passaram a estar presentes na pauta diária da década de 1960, permeados pelos conceitos de moderno e modernização. Motta (2014), ao discorrer sobre a onda modernizadora, refere-se ao contexto internacional da Guerra Fria.

\footnotetext{
Alguns dos modelos mais influentes vinham da academia e das agências estatais norte-americanas, cujas teorias se pautavam pelos imperativos da Guerra Fria. Na acepção das teorias da modernização elaboradas por cientistas sociais americanos e encampadas pelo governo dos Estados Unidos, principalmente na gestão de Kennedy, a melhor maneira de vencer o desafio revolucionário era modernizar os países "atrasados", considerados presas fáceis do inimigo comunista. $\mathrm{E}$ a educação era um dos setores prioritários da pauta modernizadora, por seus efeitos multiplicadores e por incutir valores nos jovens (MOTTA, 2014, p. 910).
}

Em 31 de março de 1964, durante a Guerra Fria, e em meio a uma crise política no governo do presidente João Goulart, efetivou-se o Golpe Militar. Segundo Fausto (2015), o movimento de 31 de março foi lançado, aparentemente, 
para livrar o país da corrupção e do comunismo e para restaurar a democracia. No entanto, a data marcou o início de um período de 21 anos de ditadura militar no Brasil.

De acordo com Motta (2014), a modernização do país, já em pauta antes da chegada dos militares ao poder, foi uma das bandeiras estabelecidas pelos governos no período da ditadura, interessados no aprimoramento de áreas consideradas estratégicas para o desenvolvimento econômico e para a modernização. Os militares se alinharam com os diplomatas americanos, que pressionavam os aliados brasileiros a adotarem políticas modernizadoras e ao mesmo tempo injetavam recursos e financiamentos. Ainda conforme Motta (2014), nos meses imediatamente posteriores ao Golpe, vários convênios, acordos e contratos foram estabelecidos entre Brasil e Estados Unidos (EUA) ${ }^{1}$.

Para a implantação da modernização, foi promulgada, em 1968, a Lei no 5540, conhecida como Reforma Universitária. Os primeiros textos legais com fundamentos dessa reforma, entretanto, foram editados em 1966 e 1967. Tratase dos Decretos-Lei no ${ }^{0}$ 53, de 18 de novembro de 1966, e n ${ }^{\circ} 252$, de 28 de fevereiro de 1967. O primeiro definia que caberia às universidades dedicar-se, simultaneamente, às atividades de pesquisa e extensão. Outro ponto importante desse decreto é que seu texto deixava implícita a intenção de redefinir as antigas faculdades de filosofia e ciências, com a criação de novas unidades, de preferência institutos, destinados às ciências naturais. O Decreto $\mathrm{n}^{0} 252$ trazia como novidade a definição dos departamentos como subunidades básicas das universidades (MOTTA, 2014). Segundo Motta (2014, p. 108), a Lei n. 5540

foi o resultado das ações e dos projetos de forças díspares, que se aliaram e/ou se enfrentaram ao longo dos anos de 1960, com destaque para estudantes, professores, cientistas, militares e técnicos da área econômica.

\footnotetext{
${ }^{1}$ Dentre eles, os acordos entre o MEC e a Usaid - United States Agency for International Development - assinados em meados de 1965 , foram os que alcançaram maior notoriedade.
} 
A Reforma Universitária compendiou os Decretos-Lei ${ }^{0} 53$ e $\mathrm{n}^{0} 25^{2}$ e trouxe novidades, como a extinção das cátedras, o fortalecimento das instituições centrais da universidade, o vestibular unificado e classificatório, a instituição do regime de trabalho em tempo integral para docentes e o ciclo básico para os cursos de graduação.

Por um lado, a Reforma foi responsável pela modernização de uma parte significativa das universidades federais, estaduais e confessionais, à medida que essas instituições incorporaram as modificações propostas pela lei. Por outro lado, ao permitir a existência de "instituições isoladas", já estabelecidas na Lei de Diretrizes e Bases (LDB) de 1961, a Reforma criou condições favoráveis ao processo de privatização do ensino superior.

Vários fatores contribuíram para a ampliação das instituições particulares de ensino superior naquela época. No processo de expansão, destacase o papel do Conselho Federal de Educação (CFE), que, desde a LDB de 1961, passou a deliberar sobre a abertura e funcionamento de instituições de ensino superior. Segundo Martins (2009), o CFE era composto predominantemente por personagens ligadas ao ensino privado, com disposição favorável para acolher os pedidos de abertura de novas instituições particulares. O autor destaca que a grande maioria dessas solicitações emanava da iniciativa privada nãoconfessional, que percebeu a existência de uma demanda não atendida pelo ensino público.

Foi no contexto de ditadura militar e de expansão do ensino superior privado que se deu a criação da primeira instituição de ensino superior em Governador Valadares, Minas Gerais. Trata-se do Minas Instituto de Tecnologia (MIT), uma das instituições que veio a compor a atual Universidade Vale do Rio Doce (Univale). Neste artigo, abordamos aspectos da criação e dos primeiros tempos de existência do MIT, apresentando resultados de uma pesquisa (ROQUE, 2019) cujo objeto foi o curso de licenciatura em Matemática da instituição.

O estudo se desenvolve em várias seções, que abordam as fontes 
utilizadas, o contexto de implantação do MIT em Governador Valadares, o papel de Talmir Canuto Costa nesse movimento, os nomes da instituição e a relevância da sigla MIT em sua trajetória, o oferecimento de licenciaturas em seus primeiros momentos.

\section{FONTES DE PESQUISA E O DESTAQUE DA HISTÓRIA ORAL}

O presente artigo resulta do estudo de fontes diversificadas, escritas e orais. Na documentação escrita, foram consultados pareceres do Conselho Federal de Educação, jornais, históricos escolares e outros documentos institucionais do MIT-Univale. Um papel fundamental foi o dos depoimentos concedidos em entrevistas com 16 sujeitos que foram professores e alunos da instituição. Essas entrevistas foram conduzidas pela metodologia da História Oral e geraram narrativas gravadas, transcritas e textualizadas ${ }^{2}$. Passagens das entrevistas com quatro sujeitos presentes nos primeiros momentos do MIT são usadas neste artigo.

A História Oral é uma metodologia de pesquisa e de constituição de fontes que consiste na realização de entrevistas gravadas com indivíduos participantes ou testemunhas de acontecimentos e conjunturas do passado e do presente. Segundo Silva e Souza (2007), a História Oral traz consigo uma intenção comum a qualquer área que dela se utiliza, que é a de valorizar narrativas orais como fontes históricas. Do ponto de vista defendido pela História Oral, a História passa a ter uma finalidade social diferente na medida em que, analisando narrativas orais, desafia as memórias institucionais dos centros de poder responsáveis por uma gama de documentação escrita, que durante muito

\footnotetext{
${ }^{2}$ A textualização é um texto editado da transcrição da entrevista, em que são retiradas as marcas mais fortes da oralidade e as falas são, por vezes, reorganizadas tematicamente. Tivemos como horizonte preservar o tom das entrevistas, de modo que nossos colaboradores se reconhecessem nas textualizações. Todos os entrevistados assinaram cartas de cessão de direitos de suas narrativas, após terem examinado e, algumas vezes, proposto modificações nas textualizações.
} 
tempo foi considerada a única evidência para pesquisa (PORTELLI, 2000). A História Oral pode trazer à tona nuances do passado que por vezes são inatingíveis em outras formas de documentação.

Para Garnica (2010, p. 291), "afirmar que um trabalho tem como metodologia a História Oral significa antes de qualquer coisa, que o trabalho cuida de constituir fontes das quais ele próprio - e outros - podem nutrir-se para focar determinados objetos de pesquisa”. Essas fontes são historiográficas por registrarem perspectivas de modo comprometido, responsável e ético; por serem o registro de uma verdade - a verdade do sujeito; por falar de um tempo, de uma condição, de um espaço, de um modo de existir, de falar, de se portar; são historiográficas em um contexto em que a historiografia aceita como legítima a presença de subjetividades (GARNICA, 2004, p. 89).

Essa característica intencional de constituir fontes históricas distingue os trabalhos que utilizam a metodologia da História Oral de outros que usam entrevistas e suas transcrições e que, em algum momento, podem vir a se tornar fontes para pesquisas historiográficas.

Ao elaborar suas narrativas, os sujeitos mobilizam sua memória e revisitam acontecimentos passados com o olhar do presente, que analisa suas experiências e, muitas vezes, quer encontrar nelas uma sequência lógica na qual um acontecimento justifica outro que o sucede. $\mathrm{O}$ que os nossos entrevistados nos relataram revelou sua perspectiva sobre o ocorrido no passado no momento da entrevista. $\mathrm{O}$ ato de narrar não apenas expressa o vivido, ele também o produz. "As vozes não refletem a realidade por si mesmas, elas constroem discursivamente um mundo vivido pelos atores” (BOLÍVAR, 2002, p. 25).

Tendo presentes essas considerações, fazemos uso, neste trabalho, de partes das narrativas de Talmir Canuto Costa, Tatiana Castello Branco Rodrigues Coelho, Maria Cristina Ponciano de Lima e Marli Elias Pereira, que, como docentes e discentes, estiveram vinculados ao MIT em seus primeiros anos de existência. 


\section{DESENVOLVIMENTO, MODERNIZAÇÃO E ENSINO SUPERIOR: A IMPLANTAÇÃO DO MIT EM GOVERNADOR VALADARES}

Governador Valadares está localizada no leste de Minas Gerais, faz parte da mesorregião Vale do Rio Doce e, segundo dados do Censo de 2010, sua população era de 263.689 habitantes. O surgimento da cidade se relaciona ao movimento de povoação da Bacia do Rio Doce, iniciado no século XVIII. Na primeira metade do século XIX, às margens do Rio Doce, aos pés do Pico do Ibituruna, surgiu um povoado que, em 1884, passou a ser um distrito subordinado ao município de Peçanha e, em 1937, se tornou um município, tendo recebido seu nome atual, Governador Valadares (IBGE, 1959; COSTA, 1977), em 1938. O nome da cidade representa uma homenagem ao interventor do estado nomeado por Getúlio Vargas3 em substituição a Olegário Maciel4, o governador falecido em 1933, durante o mandato.

Desde o começo, o povoado se configurou como um entreposto comercial para trocas de excedentes da região pelos produtos industrializados vindos do litoral. Inicialmente feito pelo Rio Doce, com a inauguração da ferrovia VitóriaMinas, em 1910, o escoamento do café e de outros produtos passou a ser realizado pele rede ferroviária. Com a queda da produção do café, reflexo da crise que acometia todo o país, começou a exploração dos recursos naturais da região, especialmente a madeira, e a criação do gado de corte. A economia de Governador Valadares passou a ser caracterizada, então, por ciclos extrativistas não sustentáveis, como os de madeira e mica. A pecuária extensiva se expandiu com o êxodo rural ocorrido depois de 1955 e a cidade foi marcada, por fim, pelo fenômeno da emigração, especialmente para os EUA, a partir da década de 1980, devido ao período de estagnação econômica que se deu então (SANTOS, 2014).

Foi na década de 1960, quando a população era de 120 mil habitantes,

\footnotetext{
3 Benedito Valadares permaneceu no governo de Minas Gerais por 12 anos.

4 Não havia vice-governador desde 1931, pois ele havia renunciado ao cargo.
} 
que passou a circular na cidade, especialmente gerado pela fala das lideranças políticas, um discurso de modernidade, e várias medidas foram tomadas nesse sentido, destacando-se as obras de infraestrutura e reforma urbana. Esse discurso de modernidade reflete o contexto brasileiro da época, no qual o apelo por desenvolvimento e modernização era forte e sedutor e havia pressão internacional, sobretudo dos Estados Unidos, para a adoção de políticas modernizadoras (MOTTA, 2014). Especificamente em 1967, foi implantada a primeira escola de ensino superior em Governador Valadares, o Minas Instituto de Tecnologia (MIT), uma das instituições que veio a formar a atual Universidade Vale do Rio Doce (Univale) e que ofertou seus primeiros cursos no ano de 1968.

As movimentações iniciais para a criação da primeira instituição de ensino superior em Governador Valadares tiveram início na segunda metade da década de 1960, com a chegada do Brigadeiro George Soares de Moraes5 à cidade.

Conforme Talmir Canuto Costa, um de nossos entrevistados, George Soares de Moraes, após aposentar-se do Instituto Tecnológico de Aeronáutica (ITA), ligado ao Centro Tecnológico Aeroespacial (CTA), em São José dos Campos, mudou-se para Governador Valadares a fim de ajudar seu pai, Amintas Jaques de Moraes, na condução de uma usina siderúrgica chamada Sinval ${ }^{6}$. Juntamente com Antonio Rodrigues Coelho, seu sócio na Sinval, George Soares de Moraes começou a cogitar na viabilidade da criação de um Centro Tecnológico em Governador Valadares. Valendo-se de suas estreitas relações com o ITA, consultou a opinião do fundador dessa instituição, o Marechal Casimiro Montenegro Filho, que aprovou a ideia.

\footnotetext{
5 George Soares de Moraes nasceu em Belo Horizonte no ano de 1925. Em 1943, formou-se como aspirante a oficial aviador e, em 1949, formou-se como engenheiro metalúrgico pela atual Carnegie Mellon University (EUA). Foi professor associado e gestor do ITA. Fontes: http://www1.folha.uol.com.br/fsp/cotidian/ff1108200112.htm, http://www.aeitaonline.com.br/wiki/index.php?title=George_Soares_Moraes. Acesso em: 20 jul. 2017.

${ }^{6}$ Usina Siderúrgica Valadares, que depois passou a se chamar Fertimetal, era uma empresa de produção de ferro-gusa fundada em 1966 na cidade de Governador Valadares. Fonte: http://www.econodata.com.br/lista_empresas/MINAS-GERAIS/GOVERNADORVALADARES/F/20599601000170-FERTIMETAL-METAIS-SA. Acesso em: 16 abr. 2017.
} 
Ele [George de Moraes] chegou a conversar com o Marechal Casimiro Montenegro Filho, que foi o fundador do ITA, o grande homem do ITA, tendo achado que era viável fazer uma coisa dessas lá no leste mineiro7 (Talmir Canuto Costa).

Uma característica fundamental do ITA, desde a sua fundação, é o caráter inovador. Segundo Veiga (2007), o ITA foi fundado em 1947, em São José dos Campos, subordinado ao Ministério da Aeronáutica, dedicando-se à formação de engenheiros e ao desenvolvimento da pesquisa aeronáutica. "Sua estrutura, desde a fundação, foi caracterizada pela tradição universitária dos Estados Unidos: ausência de cátedras vitalícias e organização departamental, dedicação exclusiva dos professores no ensino e pesquisa e pós-graduação" (Idem, p. 302). Conforme foi dito antes, esse foi o tipo de organização proposta e aplicada nas universidades brasileiras a partir da reforma universitária de 1968.

Os passos seguintes para a constituição da primeira escola de ensino superior em Governador Valadares foram dados no sentido de buscar o apoio da liderança política e econômica da cidade.

Ele foi para a reserva como brigadeiro e depois foi fazer esse trabalho na Sinval, porque ele era metalurgista. Quando chegou lá, viu que poderia ser implantado em Governador Valadares um Instituto Tecnológico, de iniciativa privada. Então manteve contato com a comunidade; a comunidade que eu digo são os líderes da comunidade, e eles começaram a desenvolver esse trabalho (Talmir Canuto Costa).

Em 1967, o jornal Diário do Rio Doce publicou várias matérias de primeira página para divulgar ações para a constituição dessa escola superior. Destacam-se aquelas em que se buscava envolver a comunidade, como reuniões e palestras.

Tatiana, sobrinha de Hermírio Gomes da Silva, que assumiu a Prefeitura de Governador Valadares a partir de 1967, falou do envolvimento e do apoio do

7 Ao longo do artigo, as falas dos entrevistados serão apresentadas em itálicos. 
tio para a criação da instituição.

Foi assim, com uma alegria muito grande, que eu vi surgirem as primeiras iniciativas para se criar curso superior em Governador Valadares. O prefeito era Hermírio Gomes da Silva - minha mãe é irmã dele - e então a gente viu essas [...] essa germinação de dentro de casa. Era a conversa de dentro de casa quando ele ia na casa dos meus avós. Quando a gente estava sentada à mesa de almoço conversando [...]. Então, essa é uma história que eu vivi do comecinho (Tatiana Castello B. R. Coelho).

O Plano Básico, com as diretrizes gerais para a criação do Centro Tecnológico, foi elaborado por Ernesto Luiz de Oliveira Júnior, a pedido de George Soares de Moraes, e apresentado no dia 27 de fevereiro de 1967 (CAMPOS, 2007, p. 17). A ideia era constituir o Centro por uma série de Minas Institutos, e o primeiro deles seria denominado MIT-Minas Instituto de Tecnologia, que iniciaria suas atividades com cursos de Engenharia.

De acordo com o Parecer $n^{0} 641$ de 1968 do Conselho Federal de Educação (CFE) (BRASIL, 1968b), a criação desse Centro Tecnológico estava em consonância com o esforço e o anseio desenvolvimentista do País. Esse discurso do CFE se sintonizava com o dos militares no comando do país naquela época. Conforme Motta (2014), a modernização do Brasil foi uma das metas estabelecidas pelos militares no período da ditadura e era seu interesse o desenvolvimento de áreas consideradas estratégicas para o desenvolvimento econômico e para a modernização.

Nesse sentido, a tradição bacharelesca das universidades e o número elevado de matriculados nos cursos de humanidades em detrimento das áreas científica e tecnológica foram criticados. Para atender as necessidades da indústria em expansão, das atividades produtivas e da própria máquina do Estado, enfatizou-se a necessidade de aumentar as vagas das áreas científica e tecnológica. Nessa época, surgiram muitas instituições dedicadas à formação e educação superior tecnológica, as chamadas faculdades tecnológicas. Elas se 
preocupavam em formar profissionais com perfil voltado para o mundo do trabalho, os técnicos de nível superior (PRADO, 2018). No caso da instituição de Governador Valadares, embora seu nome incluísse o termo "Tecnologia", a intenção não era criar uma faculdade tecnológica. Desde o início, conforme o relato de Talmir, o modelo proposto foi o Instituto Tecnológico de Aeronáutica, que inspirou o nome do MIT.

Embora não sejam classificadas como cursos técnicos de nível superior, as engenharias, como ciências aplicadas, se vinculavam a setores dinâmicos da economia, e eram cursos propícios naquele momento de crescimento econômico e industrial. Por isso, não é de se estranhar que a abertura do MIT tenha sido vista com um olhar favorável por parte do CFE.

Segundo Cacete (2014), a expansão do ensino superior no Brasil a partir da década de 1950 esteve muito ligada à fundação de faculdades isoladas de filosofia, ciências e letras. As décadas de 1960 e 1970 foram marcadas pela grande expansão do setor privado a partir da criação de inúmeras dessas faculdades. Alguns fatores contribuíram para isso: a expansão da oferta da educação escolar, ocorrida nesse período, gerando a necessidade de formar professores para dar conta da demanda; o fato de essas faculdades exigirem poucos recursos financeiros para serem implantadas; e o processo de interiorização do ensino superior. Além disso, a LDB de 1961 trouxe, em seu artigo 59, a exigência de formação nessas faculdades para lecionar no ensino médio.

Com a reforma do Ensino Superior de 1968, essa exigência foi extinta, podendo a formação ser feita, nas universidades, mediante a cooperação das unidades responsáveis pelos estudos incluídos nos currículos. No entanto, mesmo após essa possibilidade, a criação das licenciaturas no âmbito das faculdades de filosofia, ciências e letras continuou predominando (CACETE, 2014). Assim, a instituição de ensino superior criada em Governador Valadares foge ao padrão dominante de ampliação dos cursos superiores do período.

Embora fora da tendência de implantação do ensino superior naquele momento, a criação de um instituto de tecnologia com oferta de cursos de 
Engenharia está em total conformidade com as metas desenvolvimentistas do governo naquela época. Além disso, as ligações acadêmicas anteriores do Brigadeiro George Soares de Moraes com os militares e sua experiência no ITA são elementos que contribuem para entender sua intenção.

\section{O PAPEL DE TALMIR CANUTO COSTA NA CONSTITUIÇÃO DO MIT}

Para efetivar o projeto do instituto de tecnologia em Governador Valadares, foi escolhido e convidado Talmir Canuto Costa, um professor paulista que havia sido engenheiro subordinado a George de Moraes no CTA.

Como a coisa já estava adiantada, ele precisava ter uma pessoa que pudesse levar esse projeto à frente. Foi quando ele se lembrou de mim, porque eu tinha sido seu engenheiro no CTA e porque ele soube que eu havia montado a Escola de Engenharia de Taubaté. Nessa Escola de Engenharia de Taubaté, que foi basicamente a semente da universidade, eu fiquei cinco anos, até formar a primeira turma, e fui até paraninfo da primeira turma. E então ele me convidou para ir lá (Talmir Canuto Costa).

Bom, e quem vai conduzir isso? O brigadeiro George de Moraes disse que sabia de uma pessoa e foi atrás. O Dr. Talmir Canuto Costa ... [...] E ele veio! Ele estava com uma bolsa, ia estudar na $N A S A^{8}$. Ele vai te contar essa história com certeza, porque tinha feito o trabalho dele de mestrado em baterias solares e estava com uma proposta para ir para a NASA para desenvolver pesquisa e continuar os estudos nessa área. Segundo depoimento que ele deu, e falou comigo pessoalmente uma vez, "eu vim para cá porque achei que ia ser mais útil ao Brasil criando essa escola de Engenharia do que indo para a NASA, porque talvez eu não voltasse" (Tatiana Castello B. R. Coelho).

A escolha de Talmir como líder do empreendimento não foi um acaso, pois ele tinha experiência e credenciais que facilitariam o processo de implantação da instituição. Talmir tinha, ainda, contatos anteriores que

\footnotetext{
8 National Aeronautics and Space Administration.
} 
poderiam favorecer o estabelecimento do MIT. Embora civil, Talmir mantinha boas relações com os militares, que governavam o país. Ao se apresentar na entrevista, ele contou, por exemplo, que em certo momento tinha aceitado assumir a reitoria do ITA em caráter pro tempore.

\begin{abstract}
Bom, eu fiz esse resumo, mas há três eventos no meio do caminho que posso citar. Um, eu fui reitor do ITA em 1965. Isso aconteceu porque houve uma crise institucional dos professores do ITA com o Diretor Geral do CTA. O Diretor Geral era escolhido pelo ministro da Aeronáutica e eles, digamos, não estavam se entendendo muito bem com o reitor e os professores do ITA. Então o Diretor Geral, para não colocar um militar dentro do ITA, concordou que fosse escolhido um ex-aluno do ITA, um aluno graduado no ITA, para assumir a reitoria. E como eu era o mais qualificado pesquisador do CTA graduado no ITA, fui convidado para pegar a reitoria em caráter pro tempore. Depois que as coisas se acalmaram, passei para um professor (Talmir Canuto Costa).
\end{abstract}

Em um período em que a influência estadunidense no Brasil era intensa, de modo especial na área da educação, Talmir representava uma figura com trânsito no âmbito dos Estados Unidos. Tinha feito a graduação e o mestrado no ITA, cujo quadro docente contava com vários professores oriundos daquele país. Havia recebido o convite para trabalhar na NASA e, posteriormente, foi chamado pelo Adido Cultural dos Estados Unidos no Brasil para conhecer várias universidades no país. Entendemos que, em um contexto de autoritarismo político, no qual as relações interpessoais contavam muito, a proximidade de Talmir com os militares e suas boas relações com os norte-americanos contribuíram para a implementação do MIT e repercutiram na maneira como ele conduziu seu trabalho na instituição.

De acordo com o Art. 85 da Lei 4.024 de 1961 (LDB/61), os estabelecimentos isolados de ensino superior deveriam ser constituídos sob a forma de autarquias, fundações ou associações. No caso de Governador Valadares, decidiu-se criar uma fundação para ser a entidade mantenedora do MIT. Para a constituição dessa fundação, foram realizadas, no ano de 1967, 
reuniões envolvendo os idealizadores e a comunidade, que resultaram na escolha do nome Fundação Percival Farquhar, em homenagem a um engenheiro estadunidense envolvido diretamente com negócios da siderurgia no Brasil9. A fundação foi constituída legalmente em reunião convocada pelo jornal Diário do Rio Doce no dia 25 de abril de 1967.

Dois professores de São José dos Campos, Talmir e Francisco de Castro Pimentel ${ }^{10}$, foram convidados a irem a Governador Valadares para orientarem os coordenadores do MIT na estruturação da Fundação Percival Faquhar. Talmir relatou que chegou à cidade, pela primeira vez, na noite de 14 de maio, quando se encontrou com George de Moraes para conversarem sobre o empreendimento.

\begin{abstract}
Bom, eu não conhecia Governador Valadares, não conhecia aquela região de maneira nenhuma ... E ele convidou também o Francisco de Castro Pimentel, que era assessor jurídico do diretor geral do CTA, e nós dois combinamos de viajar a Governador Valadares. Fomos daqui para lá, de carrinho, um Fiatzinho, e chegamos lá tarde, porque viajamos o dia todo. Chegamos mais ou menos umas 11 horas da noite e o carro até parou na entrada da ponte de Valadares, na Rio-Bahia, porque teve problema de gasolina. A gente chamou o George Moraes, e o senhor Antonio Rodrigues Coelho que era, na ocasião, um grande esteio da Fundação Percival Farquhar, foi nos buscar e nos levou até o George Moraes. Nos encontramos por volta de 11 e meia da noite, na usina Sinval, que depois se chamou Fertimetal. Nesse encontro, ele nos contou qual era a sua ideia sobre a instituição e, no dia seguinte, teve uma grande reunião no cinema da cidade para arrecadar recursos para a Fundação, para o patrimônio da Fundação. Nós fomos a essa reunião, o pessoal se entusiasmou muito e até eu e o Pimentel
\end{abstract}

\footnotetext{
9 Percival Farquhar (1864-1953) esteve envolvido em vários negócios no Brasil: montagem da Light, no Rio de Janeiro, construção da Estrada de Ferro Madeira-Mamoré, criação da empresa Port of Pará, exploração de borracha, montagem de ferrovia para o Rio Grande do Sul, dentre outras. Suas iniciativas, dentre as quais algumas tiveram sucesso e outras não, forjaram para ele uma imagem contraditória. Alguns o taxaram de "explorador do Brasil" e outros o consideram digno de reconhecimento (COELHO, 2011; CAMPOS, 2007).

${ }^{10}$ Francisco José de Castro Pimentel era formado em Direito e foi assessor jurídico do diretor do Centro Técnico da Aeronáutica, em São José dos Campos. Foi secretário e diretor da Faculdade de Direito Vale do Paraíba, em São José dos Campos. Fontes: http://www.fab.mil.br/files/agraciados_msants_dumont.pdf, http://www.pucsp.br/comissaodaverdade/downloads/docs-sabbag/sabbag-doc-2escolaridade.pdf, https://www.univap.br/arquivo/Crescimento\%20de\%20SJC\%20e\%20a\%20cria\%C3\%A7\%C3 \%A3o\%20da\%20Faculdade\%20.pdf?AID=1159. Acesso em: 26 mar. 2018.
} 
participamos com uma contribuição financeira. E voltamos para São José (Talmir Canuto Costa).

A vinda de Talmir foi matéria de primeira página do jornal Diário do Rio Doce de 14 de maio de 1967, com a manchete: "Professor do ITA veio esquematizar o MIT”. Em matéria do dia 16 de maio, percebe-se que na reunião do dia 15 de maio ele já tinha assumido um papel de liderança frente ao MIT.

Já em sua primeira visita a Governador Valadares, Talmir iniciou seus contatos com a comunidade local e, após duas reuniões, voltou para São José dos Campos. Segundo Campos (2007), em 22 de julho de 1967, ele mudou-se definitivamente para a cidade. O início do trabalho no MIT foi narrado por Talmir.

\begin{abstract}
Então fui para Valadares nesse comecinho da Fundação. Chegando em Valadares, como não tinha nenhum curso superior lá, o ambiente educacional de nível superior era muito incipiente. Então comecei do zero em Valadares. Nós começamos ali na Avenida Minas Gerais, na Praça Serra Lima, em um escritoriozinho onde ficávamos eu e a dona Therezinha ${ }^{11}$. A Therezinha ficava lá e a gente ficava mantendo contato com pessoas: possiveis alunos e professores, e pessoas que pudessem e quisessem entrar nesse empreendimento. Foi assim que se começou (Talmir Canuto Costa).
\end{abstract}

A aprovação da conveniência da criação do MIT foi dada pelo Conselho Federal de Educação, por meio do Parecer $n^{0} 323$ de $1967^{12}$, e a autorização para seu funcionamento pelo Parecer $n^{\circ} 28$ de 1968 (BRASIL, 1968a). A ideia dos fundadores, criar um instituto de tecnologia nos moldes do ITA, possivelmente contribuiu para uma acolhida favorável no CFE. Inicialmente, foram aprovadas e

\footnotetext{
${ }^{11}$ Segundo Campos (2007), Therezinha Oliveira de Almeida trabalhou por 35 anos na Fundação Percival Farquhar, começando suas atividades em 1968, ano em que assumiu o posto de secretária de Talmir Canuto Costa.

12 Não conseguimos encontrar a revista Documenta na qual foi publicado esse parecer, por isso essa referência não consta em nossa lista. Para ter acesso a ele, fizemos o pedido no sistema de Acesso à Informação, no site http://www.acessoainformacao.gov.br/, a partir do qual chegamos à cópia do parecer manuscrito.
} 
ofertadas 200 vagas para os cursos de Engenharia Metalúrgica, Engenharia Mecânica e Engenharia de Operações Industriais.

A chegada de uma instituição de ensino superior nas cidades do interior representava, naquela época, um sinal de que havia progresso (CACETE, 2014). Em Governador Valadares, parece não ter sido diferente.

\begin{abstract}
A chegada do MIT foi boa economicamente, culturalmente e até para a sociedade em si, porque chegaram muitas pessoas de outras cidades. Até para as moças foi bom, porque muitas se casaram com os que foram para lá para estudar. [...] A chegada do MIT foi muito importante para Valadares. Trouxe um desenvolvimento econômico, cultural, principalmente, e Valadares se tornou uma cidade universitária! (Maria Cristina Ponciano de Lima).

Quando chegou o MIT, eu morava aqui em Governador Valadares. E a criação do MIT foi uma revolução! Porque ia abrir uma universidade. [...]Foi uma época de muitos comentários. Comentários do nosso progresso (Marli Elias Pereira).
\end{abstract}

Como ficou visível na fala de nossos entrevistados e em outras fontes, a influência de Talmir foi muito forte nos primeiros anos da instituição. É importante considerar sua trajetória de dez anos de pesquisas no CTA, em que trabalhou, de 1957 a 1967, com pesquisas na área de eletrônica e física aplicada. Como foi o grande incentivador do desenvolvimento de pesquisas no MIT em seus primeiros anos, essas pesquisas acabaram assumindo caráter mais aplicado e relacionado com as áreas técnicas (PARENTE et al., 197-).

Outro tipo de atuação significativa de Talmir foi o trabalho pela integração da nova instituição à cidade. Ele liderou a criação de algumas sociedades cujo objetivo era levar a comunidade externa para dentro da universidade: a Sociedade de Amigas da Universidade - Sodami, a Sociedade Literária - Solitier, e a Sociedade de Teatro - Sotea. Em suas palavras,

nós bolamos o seguinte: vamos montar algumas sociedades satélites da universidade. Sociedade Literária, que virou a Academia 
Valadarense de Letras, porque aí essas pessoas que são da comunidade vão se sentir integradas à universidade, ao MIT, e vão ser valorizadas. E elas começam a desenvolver um trabalho na área de literatura. A Sociedade de Amigas, que era chamada de Amigas da Universidade, Sodami, era composta de senhoras da comunidade, de prestígio. A instituição dava para elas toda a cobertura, proteção etc e tal, e elas se apresentavam na colação de grau, nos eventos, nas visitas. Nós tivemos até a visita do vice-presidente do Brasil! Então elas se apresentam e elas é que fazem o meio de campo social. E elas se sentem valorizadas: "Nós somos da universidade." (Talmir Canuto Costa).

Também o nome e a sigla do instituto tecnológico de Governador Valadares, tema de nossa próxima seção, estiveram fortemente ligados a Talmir.

\section{MIT: UMA SIGLA E O(S) NOME (S) DE UMA INSTITUIÇÃO}

O primeiro nome escolhido para a instituição foi MIT - Minas Instituto de Tecnologia. No entanto, no Parecer no 28 de 01 de fevereiro de 1968, o CFE recomendou que a designação fosse alterada, para adaptar-se "à terminologia adotada para designar os estabelecimentos de ensino superior no Brasil" (BRASIL, 1968a). Iniciou-se, com isso, em Governador Valadares, a resistência a esse parecer. Talmir, como diretor do Instituto, enviou um ofício ao CFE no qual insistia na manutenção do nome original e a defendia. O Parecer no 255 de 11 de abril de 1969 (BRASIL, 1969a), após retomar o que é dito no Parecer no 28 de 1968, afirma:

Em cumprimento das exigências acima indicadas, a Direção do Instituto envia um ofício, insistindo na permanência da designação inicialmente proposta para a escola, isto é, Minas Instituto de Tecnologia, e sugerindo duas siglas, MIT, para a qual tem preferência, ou MITec.

Alega, em apoio de sua pretensão, que já existe uma escola com o nome de Instituto de Tecnologia do Estado de Minas Gerais, o MIT é o 
primeiro Minas Instituto a ser instalado para a formação de um grande centro de Tecnologia. Lembra, ainda, ser frequente a coincidência de siglas de instituições de naturezas diversas, e, ainda o fato de estarem funcionando o Minas Engenharia de Estradas S.A., o Minas Científico, o Minas S.A. e outros mais (BRASIL, 1969a).

No entanto, o CFE, na pessoa do conselheiro Newton Sucupira, não aceitou os argumentos do diretor e insistiu na recomendação quanto à mudança do nome da instituição, alegando que a sigla MIT era conhecida como indicativa do Massachusetts Institute of Tecnology, de renome mundial. A defesa da necessidade de modificação era reforçada pela afirmativa de que a sigla contrariava a índole da língua vernácula.

Diante de mais uma recusa do CFE em aceitar o nome Minas Instituto de Tecnologia, foi proposto um novo nome para a instituição: Instituto de Tecnologia de Governador Valadares, aprovado pelo CFE no Parecer no 467 de o9 de julho de 1969 (BRASIL, 1969b). A partir de então, esse foi o nome oficialmente adotado. Observamos, porém, que houve apego da instituição à sigla MIT, que continuou a ser utilizada mesmo após essa alteração, tanto em documentos internos quanto na mídia. O diploma de Tatiana Castello Branco, datado de outubro de 1976, ainda traz a sigla ao lado do nome oficial desde 1969.

Em relação à mudança de nome da instituição e à manutenção da sigla, ao abordar o projeto inicial, baseado na criação de uma série de Minas Institutos ${ }^{13}$, Talmir assim se pronunciou:

O que acontece é que o Conselho Federal de Educação achou que não tinha que ser Minas Instituto, porque a sigla "em, ai, ti" (MIT)" era igual à do Massachusetts ${ }^{14}$, então não podia ser. Na verdade o MIT ficou famoso em vários lugares do Brasil, até o jornal Globo fez uma reportagem sobre o MIT.

\footnotetext{
${ }_{13}$ Talmir relatou que esse projeto inicial foi ideia dele, o que não corresponde às informações encontradas em Campos (2017), segundo o qual teria sido Ernesto Luiz Oliveira o responsável pelo plano básico para a criação do Centro Tecnológico idealizado por George de Moraes.

${ }^{14}$ Massachusetts Institute of Technology.
} 
E mesmo mudando o nome eu mantive o MIT. Eu coloquei Instituto de Tecnologia de Governador Valadares - MIT! Mantive o MIT. E eu mantive isso o tempo todo em todos os contatos, em tudo que era instituto! Ficou! Por isso é que pegou o MIT. Era como um nome fantasia que você não pode impedir que haja (Talmir Canuto Costa).

Percebemos que a associação do instituto de Governador Valadares, por meio da sigla, a uma instituição estadunidense célebre pela excelência acadêmica, era uma ideia muito cara a Talmir, que insistiu em preservar a sigla, apesar da modificação no nome. No início da década de 1970, houve tentativas de vincular o MIT a outras instituições para formar a Universidade Tecnológica de Governador Valadares (UTEC) e a Universidade Santos Dumont (USD). A Revista Documenta, que publicava os pareceres do CFE, e Parente et. al. (197-) esclarecem que essas instituições, que reuniriam ao MIT outras instituições municipais da cidade doadas pela Prefeitura à Fundação Percival Farquhar, não foram aprovadas pelo CFE. Em sua entrevista, Talmir manifestou indignação pela ausência de anuência desse Conselho quanto à Universidade Santos Dumont.

Santos Dumont era um nome nacional. Eu não queria colocar Universidade de Governador Valadares, porque ficava muito restrita. A minha ideia era fazer uma instituição de nível bem elevado, de âmbito bem amplo, por isso Universidade Santos Dumont. Mas esse nome não foi aprovado, porque os homens do Conselho Federal de Educação disseram: "Não, Santos Dumont tem que ser universidade da cidade Santos Dumont." Era uma mediocridade muito grande! (Talmir Canuto Costa).

O entrevistado justificou seu interesse, ligado ao ITA:

Por que eu queria que fosse Universidade Santos Dumont? Porque Santos Dumont é patrono da Aeronáutica e eu poderia manter contatos mais estreitos aqui com o CTA e levar recursos, levar muita coisa para lá (para a USD) (Talmir Canuto Costa).

Outra entrevistada, Marli, possibilitou que compreendêssemos melhor a 
indignação de Talmir ao falar de sua expectativa na criação da USD.

Essa questão da Universidade Santos Dumont era o sonho do Dr. Talmir. Ele chegou até a colocar uma réplica do aviãozinho do Santos Dumont na entrada do P $4^{15}$. Era o pensamento dele. Ele até mandou fazer a planta da universidade (Marli Elias Pereira).

A UTEC e a USD não foram instituições oficialmente formalizadas perante o CFE, embora existissem na prática, como mostram alguns certificados de conclusão de cursos de extensão de nossas entrevistadas Tatiana e Maria Cristina.

Foi apenas em 1985 que o CFE aprovou o pedido de constituição de uma universidade formada pelas instituições de ensino superior mantidas pela Fundação Percival Farquhar que, em 1989, foram reunidas e passaram a formar as Faculdades Integradas Vale do Rio Doce - Facivale. O nome escolhido para a universidade enfim aprovada foi Universidade Vale do Rio Doce - Univale. Em o7 de julho de 1992, a Univale foi oficialmente reconhecida por meio do Decreto $\mathrm{n}^{0} 1034$ de 1992.

\section{DOS CURSOS TECNOLÓGICOS AO OFERECIMENTO DE LICENCIATURAS}

As aulas dos cursos de Engenharia do MIT se iniciaram em 02 de março de 1968, conforme anunciado no jornal Diário do Rio Doce da véspera. Contudo, das 200 vagas aprovadas pelo CFE, apenas 93 foram preenchidas após a realização do primeiro vestibular.

A ociosidade das mais de 100 vagas no MIT motivou a abertura de novos cursos por parte da instituição. Como as iniciativas da Fundação Serviço de

\footnotetext{
15 De acordo com Histórico da UTEC: 1967-1975, o prédio P4 se localizava na Rua Moreira Sales, $n^{\circ}$ 850, Bairro Vila Bretas, em Governador Valadares. Nele funcionava a Administração Geral da instituição que veio a se chamar Universidade Vale do Rio Doce.
} 
Educação e Cultura (Funsec), da Prefeitura de Governador Valadares, para a criação de uma Faculdade de Filosofia e Economia não haviam tido êxito, os diretores do MIT e da Funsec se reuniram e decidiram que o MIT ofertaria alguns dos cursos previstos originalmente para a Faculdade de Filosofia. Uma matéria do Diário do Rio Doce de 7 de março de 1968 informa que o CFE havia autorizado o MIT a funcionar com um regimento que permitia a formação de professores, economistas e engenheiros. Todavia, essa informação não se coaduna com a posição do CFE apresentada no Parecer n ${ }^{0} 641$ de 1968, referente ao pedido de autorização do MIT para a abertura dos seguintes cursos de licenciatura: Sociologia, Pedagogia, Letras, Matemática, Física e Química. O CFE negou o pedido para os cursos de Sociologia, Pedagogia e Letras e alegou, em tom de crítica, que o Instituto pretendia transformar-se num híbrido de Escola de Engenharia e Faculdade de Filosofia. Segundo o relator, isso comprometeria a ideia-força motivadora da criação da instituição, que era a de ser um centro de ensino tecnológico, "em consonância com o esforço e o anseio desenvolvimentista do País” (BRASIL, 1968b, p. 14). Nesse mesmo parecer, o relator aprovou o pedido de autorização de abertura dos cursos de Matemática, Física e Química, de acordo com o trecho a seguir:

Considerando as necessidades de aproveitar os recursos disponíveis para a educação ao máximo e que o ensino tecnológico e o de ciências exatas são intimamente correlacionados, somos conduzidos a uma posição intermediária, entre conceder quanto pede o Instituto e negarlhe tudo: admitimos a conveniência de serem autorizados os cursos de Matemática, Física e Química (BRASIL, 1968b, p. 14).

Segundo o Parecer no 264 de 1970 (BRASIL, 1970a), a solicitação de autorização foi apresentada pelo MIT ao CFE em 29 de abril de 1968. Assim, as aulas de todos os cursos de licenciatura tiveram início antes mesmo da consulta ao CFE, pois as inscrições para o vestibular para os cursos de Pedagogia, Sociologia, Letras, Matemática, Física e Química se realizaram de 11 a 19 de março 
de 1968, as provas foram aplicadas nos dias 20 a 23 de março $^{16} \mathrm{e}$ as aulas tiveram início em 01 de abril de 1968 (CAMPOS, 2007).

Parece-nos que havia tamanha urgência, por parte dos diretores do MIT, na abertura de novos cursos, que foi tomada a decisão de realizar o vestibular e iniciar as aulas antes mesmo da consulta ao órgão regulador responsável pelo assunto. Parece-nos, também, que havia certo otimismo por parte dos diretores ao acreditar que o CFE não colocaria impedimento às suas intenções, o que talvez tenha se refletido na matéria do jornal Diário do Rio Doce referida anteriormente ${ }^{17}$.

O estudo de diversos documentos (ROQUE, 2019) evidenciou que os cursos de Letras e Sociologia, ainda que não aprovados pelo CFE, continuaram a funcionar em vinculação com o MIT.

No pedido de autorização feito pelo MIT ao CFE, alguns argumentos apresentados para justificar a criação dos cursos de licenciatura, incluindo o de Matemática, foram: o espaço ocioso gerado pelo não preenchimento das vagas da Engenharia, a existência de candidatos - cerca de 300 - e a real necessidade de fornecer professores para o ensino médio (BRASIL, 1968b). Entretanto, em sua entrevista, ao ser indagado sobre a motivação para a criação das licenciaturas, Talmir não se referiu a qualquer preocupação com a formação de docentes para atuar na cidade e região. Para ele, abrir licenciaturas em Matemática, Física e Química seria fundamental para qualificar pessoal para a pesquisa.

Eu vinha da parte de pesquisa e a parte de pesquisa tem, fundamentalmente, dois perfis de profissionais, até hoje ainda tem isso, mas naquela época tinha muito mais nitidamente: um perfil de profissional que faz pesquisa básica, que pode muito bem ser de licenciatura, com formação básica de Matemática, Física, Química. Os

\footnotetext{
${ }^{16}$ De acordo com as informações obtidas no jornal Diário do Rio Doce nas edições dos dias 07, 19, 20 e 21 de março de 1968.

${ }_{17}$ Embora iniciar os cursos antes da autorização do CFE tenha, em um primeiro momento, nos parecido estranho e audacioso, Martins-Salandim (2012) cita o caso de outras instituições criadas no interior de São Paulo na mesma década nas quais isso aconteceu, o que indica que tal prática não era tão incomum na época.
} 
outros, que seriam de Engenharia, são mais adequados à pesquisa aplicada. [...] Com isso, quando entrei lá para fazer o Instituto de Tecnologia, eu vi que para falar em Ciência e Tecnologia avançada você tem que ter dois tipos de profissionais: um que é o prático, o engenheiro, que é o saber fazer, e o outro é o saber conhecimento; é o ter na cabeça e que também pode, obviamente, fazer pesquisa aplicada. [...] Os licenciados estavam presentes por serem imprescindíveis para uma competência científica e tecnológica. Foi essa a motivação para não deixar de lado os licenciados de ciências exatas (Talmir Canuto Costa).

Essa motivação se diferencia da apresentada pela direção do MIT, exercida na época por Talmir, que consta no Parecer no 641 de 1968 (BRASIL, 1968b). Isso levou-nos a refletir nos possíveis porquês dessa diferença. Uma possibilidade é serem as motivações mencionadas no relato oral aquelas que realmente levaram o entrevistado a decidir abrir o curso. No documento escrito, a justificativa utilizada foi a necessidade de formar professores: naquele momento, a carência de docentes pode ter parecido um argumento mais forte perante o CFE. As narrativas orais desafiam as memórias institucionais registradas em documentações escritas (PORTELLI, 2000). Sem a História Oral, não conheceríamos outra motivação para a abertura do curso a não ser a apresentada em documentos oficiais.

Outra possibilidade para a diferença é que, dados os quase 50 anos decorridos entre a criação do curso e a entrevista, as motivações elencadas no depoimento façam parte de uma reinterpretação do passado, pois a rememoração é sempre um olhar do presente sobre o tempo pretérito. Assim, nosso entrevistado pode ter falado do que gostaria que tivesse acontecido a longo prazo e não da justificativa para a criação do curso naquele momento inicial. Como alertam Connelly e Clandinin (1995), é importante distinguir os eventos, tal como são vividos, e os eventos, tal como são contados.

Embora não tenha sido citada de maneira explícita pelos entrevistados, devemos considerar a motivação financeira que nos pareceu estar por trás da abertura dos cursos de licenciatura no MIT. A instituição havia se preparado física 
e materialmente para receber 200 estudantes nos cursos de Engenharia. Na entrevista, quando se comentou sobre o uso das instalações ociosas para os cursos de licenciatura, Talmir concordou.

Isso! Exatamente! Exatamente! Porque as instalações foram bem dimensionadas para o número aprovado de vagas (Talmir Canuto Costa).

A manutenção da instituição estaria comprometida sem as mensalidades planejadas para serem pagas por mais do dobro dos alunos aprovados no vestibular das Engenharias. Os cursos de licenciatura já tinham sido mencionados por Talmir antes mesmo de esse vestibular ter sido realizado, como noticiou o Diário do Rio Doce de 16 de maio de 1967. E o parecer de autorização de funcionamento do MIT, o de $\mathrm{n}^{0} 323$ de 1967, nada diz acerca das licenciaturas. Comparados com as Engenharias, que exigiam uma infraestrutura mais complexa e cara, com laboratórios e equipamentos específicos, os cursos de licenciatura eram mais baratos e não exigiriam muito mais da Fundação Percival Farquhar além da contratação de novos professores, especialmente para os cursos de Ciências Humanas.

Como havia interesse da comunidade pelos cursos de licenciatura, a abertura desses cursos representava uma certeza de mais recursos financeiros para a manuntenção do MIT e garantia o desenvolvimento dos cursos originalmente pensados para a instituição. Essa necessidade financeira pode justificar, inclusive, a subversão da legislação caracterizada pela abertura dos cursos antes da autorização do CFE. Além disso, pode explicar, também, a opção por oferecer licenciaturas e não bacharelados, que seriam mais dirigidos à pesquisa, objetivo indicado por Talmir. Provavelmente não haveria público para os bacharelados como houve para as licenciaturas. 


\section{CONSIDERAÇÕES FINAIS}

O estudo aqui apresentado resulta de uma investigação acerca da licenciatura em Matemática originalmente criada no MIT. Uma particularidade desse curso é o tipo de instituição no qual foi criado. A criação de um curso de Matemática em um Instituto de Tecnologia destoa do padrão de implantação desse curso em outras instituições do Brasil no mesmo período ${ }^{18}$. Na década de 1960, pelo menos até a promulgação da lei de Reforma do Ensino Superior, em 1968, as faculdades de filosofia continuaram responsáveis pela oferta de cursos de licenciatura. A abertura de um curso de Matemática em um instituto de tecnologia, destinado à formação de engenheiros, era incomum à época e nos dá elementos que contribuem para compreendermos o lugar ocupado na formação do professor na instituição por um longo período.

Ficou claro que o surgimento do curso foi um subproduto do anseio modernizador e desenvolvimentista que, integrado a diversos fatores, propôs e realizou o projeto do MIT. Conquanto os cursos de licenciatura em Física, Química e Matemática tenham sido apresentados, na fala de Talmir, como pontos de partida para a pesquisa básica que ele considerava necessária, evidenciou-se que a justificativa da carência de professores foi argumento essencial para a aprovação do CFE. A possibilidade de aproveitamento da estrutura do MIT, bem como de boa parte dos professores dos cursos de Engenharia, levando em conta o grande número de disciplinas comuns aos cursos na época, foi, portanto, aproveitada pela direção do MIT. Levou-se em consideração, também, o aporte de recursos que seriam originados das mensalidades dos licenciandos.

A formação de professores, na fase inicial do curso, de 1968 até sua

\footnotetext{
${ }^{18}$ Na década de 1960, no interior de São Paulo foram criados nove cursos de Matemática. Dos oito que eram de licenciatura, sete foram criados em faculdades de Filosofia, Ciências e Letras (MARTINS-SALANDIM, 2012). O curso de Matemática investigado por Castro e Almeida (2015), o primeiro da cidade de Montes Claros - MG, criado em 1968, também surgiu no interior de uma faculdade de filosofia. O mesmo aconteceu no caso do primeiro curso de licenciatura em Matemática do estado do Maranhão, estabelecido ao final da década de 1960 (FERNANDES, 2011), e do primeiro curso de Matemática do Mato Grosso, criado em 1966, na Faculdade de Filosofia, Ciências e Letras de Cuiabá (BOTH, 2014).
} 
conversão em licenciatura curta em Ciências, efetivada em 1977, acabou por produzir parcos resultados numéricos. No fim do primeiro ano de funcionamento, havia no MIT apenas quatro licenciandos em Matemática e onze em Física. A direção do instituto chegou a propor que os alunos de Matemática migrassem para o curso de Física, o que eles recusaram. Entretanto, foi elaborado um currículo no qual se aproveitavam disciplinas obrigatórias de um dos cursos como optativa para o outro, possibilitando economia. Além disso, havia grande proximidade entre as grades curriculares das licenciaturas em Matemática e as das Engenharias, como uma maneira de equilibrar o número reduzido de alunos e professores no início da instituição.

Essa proximidade, juntamente com a falta de discussão institucional sobre a formação de professores, conforme os entrevistados, nos leva a interpretar o papel dos cursos de licenciatura como de coadjuvantes numa instituição na qual os de Engenharia eram os protagonistas naquele momento do desenvolvimentismo brasileiro sob o regime militar. Convém ressaltar que os cursos de licenciatura do MIT, mesmo tendo inicialmente formado poucos professores para o ensino escolar, acabaram fornecendo docentes para a própria instituição, que passou a contratar muitos de seus concluintes. 


\section{REFERÊNCIAS}

BOLÍVAR, Antonio. “¿De nobis ipsis silemus?”: epistemología de la investigación biográfico-narrativa en educación. Revista Electrónica de Investigación Educativa, v. 4, n. 1, 2002. Disponível em:

http://www.scielo.org.mx/scielo.php?script=sci_arttext\&pid=S160740412002000100003. Acesso em: 14 out.2021.

BOTH, Bruna Camila. Sobre a formação de professores de Matemática em Cuiabá - MT (1960-1980). 2014. 402 f. Dissertação (Mestrado em Educação Matemática) - Instituto de Geociências e Ciências Exatas, Universidade Estadual Paulista, Rio Claro, 2014.

BRASIL. Parecer $\mathrm{n}^{\circ} 28$ de 1968. Documenta. Brasília, DF: Conselho Federal de Educação no 80, 1968a.

BRASIL. Parecer n ${ }^{0} 641$ de 1968. Documenta. Brasília, DF: Conselho Federal de Educação, nº 93, 1968b.

BRASIL. Parecer $n^{0} 255$ de 1969. Documenta. Brasília, DF: Conselho Federal de Educação, no 100, 1969a.

BRASIL. Parecer no 467 de 1969. Documenta. Brasília, DF: Conselho Federal de Educação, no 103, $1969 b$.

BRASIL. Parecer $n^{0} 264$ de 1970. Documenta. Brasília, DF: Conselho Federal de Educação, no 113, 1970a.

CACETE, Núria Hanglei. Breve história do ensino superior brasileiro e da formação de professores para a escola secundária. Educação e Pesquisa, São Paulo, v. 40, n. 4, p. 1061-1076, out./dez. 2014.

CASTRO e ALMEIDA, Shirley Patrícia Nogueira de. Um lugar: muitas histórias - o processo de formação de professores de Matemática na primeira instituição de ensino superior da região de Montes Claros/norte de Minas Gerais (1960-1990). 2015. Tese (Doutorado em Educação) - Faculdade de Educação da UFMG, Belo Horizonte, 2015.

COELHO, Marco Antonio Tavares. Rio Doce: a espantosa evolução de um vale. Belo Horizonte: Autêntica Editora, 2011.

CONNELLY, Michael; CLANDININ, Jean. Relatos de experiencia e investigación narrativa. In: LARROSA, Jorge (org.). Dejame que te cuente: ensayos sobre narrativa y educación. Barcelona: Editorial Laertes, 1995. 
COSTA, Edmar Campelo. Epopéia dos Pioneiros: a História de Governador Valadares. Belo Horizonte: Ed. JM, 1977.

FAUSTO, Boris. História do Brasil. 14 ed. São Paulo: Editora da Universidade de São Paulo, 2015.

\section{FERNANDES, Déa Nunes. Sobre a formação do professor de}

Matemática no Maranhão: cartas para uma cartografia possível. 2011. 389 f. Tese (Doutorado em Educação Matemática) - Instituto de Geociências e Ciências Exatas, Universidade Estadual Paulista, Rio Claro, 2011.

GARNICA, Antonio Vicente Marafioti. História oral e educação matemática. In: BORBA, M. C.; ARAÚJO, J. L.; FIORENTINI, D.; GARNICA, A. V. M.; BICUDO, M. A. V. Pesquisa qualitativa em educação matemática. Belo Horizonte: Autêntica, 2004. (Coleção Tendências em Educação Matemática, 9).

GARNICA, Antonio Vicente Marafioti. Outras inquisições: apontamentos sobre História Oral e História da Educação Matemática. Zetetiké, v. 18, n. 34, jul./dez. 2010.

IBGE. Instituto Brasileiro de Geografia e Estatística. Enciclopédia dos municípios brasileiros. Rio de Janeiro, v. 25, p. 156-162, 1959. Disponível em: https://biblioteca.ibge.gov.br/visualizacao/livros/liv27295_25.pdf_Acesso em: 02 dez. 2017.

MARTINS, Carlos Benedito. A reforma universitária de 1968 e a abertura para o ensino superior privado no Brasil. Educação \& Sociedade, Campinas, v. 30, n. 106, p. 15-35, jan./abr. 2009. Disponível em:

https://www.scielo.br/j/es/i/2009.v30n106/. Acesso em: 14 out. 2021.

\section{MARTINS-SALANDIM, Maria Ednéia. A interiorização dos cursos de}

Matemática no estado de São Paulo: um exame da década de 1960. 2012. 379 f. Tese (Doutorado em Educação Matemática) - Universidade Estadual Paulista, Instituto de Geociências e Ciências Exatas, Rio Claro, 2012.

MOTTA, Rodrigo Pato de Sá. As universidades e o regime militar: cultura brasileira e modernização autoritária. Rio de Janeiro: Zahar, 2014.

PARENTE, Cleusa Carlos Lopes et al. UTEC histórico 1967-1975. [Governador Valadares]: [s.n], [197-].

PORTELLI, Alessandro. Memória e diálogo: desafios da história oral para a ideologia. In: FERREIRA, Maneta de Moraes; FERNANDES, Tania Maria; ALBERTI, Verena (org.). História oral: desafios para o século XXI. Rio de 
Janeiro: Editora Fiocruz, Casa Oswaldo Cruz, Centro de Pesquisa e Documentação da Fundação Getúlio Vargas, 2000. p. 67-72. Disponível em: http://static.scielo.org/scielobooks/2k2mb/pdf/ferreira-9788575412879.pdf. Acesso em: 13 jul. 2015.

ROQUE, Ana Catarina Cantoni. A formação de professores de Matemática no curso do MIT/UNIVALE: marginalidade, protagonismo e extinção (Minas Gerais, 1968-2012). 2019. Tese (Doutorado). Programa de Pósgraduação em Educação da Universidade Federal de Minas Gerais. UFMG, Belo Horizonte, 2019.

SANTOS, Wallace Ferreira dos. A invenção da cidade: Governador Valadares na trilha da modernização (1960-1970). 2014. 95 f. Dissertação (Mestrado em História) - Instituto de História, Universidade Federal de Uberlândia, 2014.

SILVA, Heloisa da; SOUZA, Luzia Aparecida de. A História Oral na pesquisa em Educação Matemática. Bolema, Rio Claro, ano 20, n. 28, p. 139-162, 2007.

VEIGA, Cynthia Greive. História da Educação. São Paulo: Ática, 2007.

ANA CATARINA CANTONI ROQUE é doutora em Educação na linha de pesquisa Educação Matemática pela Universidade Federal de Minas Gerais (2019). Professora efetiva do Instituto Federal de Educação Ciência e Tecnologia de Minas Gerais, campus Governador Valadares. Tem experiência na área de Educação Matemática, atuando principalmente nos seguintes temas: história da matemática, ensino fundamental, ensino médio, modelagem matemática e história da Educação Matemática.

E-mail: ana.catarina@ifmg.edu.br

(D) http://orcid.org/0000-0002-9357-9124

MARIA LAURA MAGALHÃES GOMES é doutora em Educação na área temática Educação Matemática pela Universidade Estadual de Campinas (2003). Professora titular aposentada da Universidade Federal de Minas Gerais (UFMG), mantém vínculo com a mesma universidade por meio de contrato de trabalho voluntário com o Departamento de Matemática do Instituto de Ciências Exatas (ICEX). É bolsista de produtividade do CNPq e membro permanente do corpo docente do Programa de Pós-Graduação em Educação: Conhecimento e Inclusão Social, também da UFMG.

E-mail: mlauramgomes@gmail.com

(ib) http://orcid.org/0000-0003-2423-7750 
Revista História da Educação (Online), 2021, v. 25: e107098 DOI: http://dx.doi.org/10.1590/2236-3459/107098

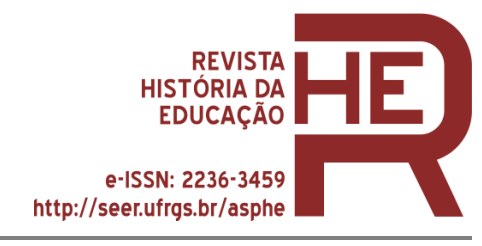

